\title{
Deciphering the neuronal circuitry controlling local blood flow in the cerebral cortex with optogenetics in PV::Cre transgenic mice
}

\author{
Alan Urban* , Armelle Rancillac, Lucie Martinez and Jean Rossier* \\ Laboratoire de Neurobiologie, Equipe Optogenetics and Brain Imaging, CNRS UMR 7637, Ecole Supérieure de Physique et de Chimie Industrielles ParisTech, PARIS, \\ France
}

\section{Edited by:}

Yuri Zilberter, Institut National de la Santé et de la Recherche Médicale, France

Reviewed by:

Enrico Sanna, University of Cagliari, Italy

Piotr Bregestovski, Institut de Neurobiologie de la Méditerranée Marseille, France

*Correspondence:

Alan Urban and Jean Rossier, Laboratoire de Neurobiologie, Optogenetics and Brain Imaging, CNRS UMR 7637, Ecole Supérieure de Physique et de Chimie Industrielles ParisTech, 10 rue Vauquelin, 75005 PARIS, France. e-mail: alan.urban@espci.fr. jean.rossier@espci.fr
Although it is know since more than a century that neuronal activity is coupled to blood supply regulation, the underlying pathways remains to be identified. In the brain, neuronal activation triggers a local increase of cerebral blood flow (CBF) that is controlled by the neurogliovascular unit composed of terminals of neurons, astrocytes, and blood vessel muscles. It is generally accepted that the regulation of the neurogliovascular unit is adjusted to local metabolic demand by local circuits. Today experimental data led us to realize that the regulatory mechanisms are more complex and that a neuronal system within the brain is devoted to the control of local brain-blood flow. Recent optogenetic experiments combined with functional magnetic resonance imaging have revealed that light stimulation of neurons expressing the calcium binding protein parvalbumin $(\mathrm{PV})$ is associated with positive blood oxygen level-dependent (BOLD) signal in the corresponding barrel field but also with negative BOLD in the surrounding deeper area. Here, we demonstrate that in acute brain slices, channelrhodopsin-2 (ChR2) based photostimulation of PV containing neurons gives rise to an effective contraction of penetrating arterioles. These results support the neurogenic hypothesis of a complex distributed nervous system controlling the CBF.

Keywords: neurovascular coupling, interneurons, optogenetics, parvalbumin, barrel cortex, infrared video microscopy

\section{INTRODUCTION}

Although the tight coupling between neuronal activity and local cerebral blood flow $(\mathrm{CBF})$ control is known since a century, little is yet known on the mechanisms involved. For a long time the attention of scientists was focused at the neurogliovascular unit composed of terminals of neurons, astrocytes, and blood vessel muscles. The regulation was triggered by local demand and controlled at the local level. Today we realize that the system is more complex. We have changed paradigm and view this system as a distributed nervous system within the brain specialized in the control of local blood flow (Kleinfeld et al., 2011). The brain activation is followed by a change in tone of smooth muscles that wrap around arterioles and thus control the amount of blood flowing in a particular capillary bed. A single stimulus, such as stimulation of the whisker pad in rodents, will be associated with local increase in the corresponding barrel field and decrease in the surrounding deeper area and in the opposite barrel field (Alonso Bde et al.,

\footnotetext{
Abbreviations: AAV, adeno-associated viral vector; BOLD, blood oxygen leveldependent signal; CaMKII $\alpha, \mathrm{Ca}^{2+} /$ calmodulin-dependent protein kinase II alpha subunit; CBF, cerebral blood flow; ChETA, engineered E123T Accelerated variant of ChR2; ChR2, channelrhodopsin-2; ChR2-EYFP, channelrhodopsin-2 with enhanced yellow fluorescent protein; DIO, double inverted open reading frame; FLEX, flipexcision switch; fMRI, functional magnetic resonance imaging; FS-PV, fast-spiking parvalbumin; M1, motor cortical area; ofMRI (optofMRI), method combining optogenetic with fMRI; PV, parvalbumin; PV::Cre, transgenic mouse expressing Cre recombinase under the control of the parvalbumin promoter.
}

2008; Boorman et al., 2010). Moreover, this complex response is clearly dependent of the brain state (Martin et al., 2006) and not restricted to the homotypic barrel field but extended to other brain area (Wiest et al., 2005).

The hypothesis that a specified neuronal circuit is involved in the regulation of local blood was emphasized by recent in vivo studies using optogenetics (Lee et al., 2010; Desai et al., 2011; Kahn et al., 2011). In the last few years, optogenetic has become the method of choice to trace functional neurocircuit in the brain (Urban and Rossier, 2012). One of the many advantages that optogenetic has over others methods like electrical stimulation is the minimally invasive and precise spatiotemporal activation/silencing of specific cell types (Chow et al., 2010; Zhang et al., 2010). In their recent paper, Lee et al. (2010) have used optogenetic to investigate the blood oxygen level-dependent (BOLD) response after light stimulation of different areas in adult rat brain. In their experiments, pyramidal cells of the primary motor cortex (M1) were specifically labeled after injection of an adeno-associated viral vector (AAV) AAV5-CaMKII $\alpha:: C h R 2$ (H134R)-EYFP in this area. In this construct, the channelrhodopsin-2 (ChR2) is expressed under the control of the promoter derived from alpha $\mathrm{Ca}^{2+} /$ calmodulin-dependent protein kinase II (CaMKII $\left.\alpha\right)$ particularly active in pyramids but not in GABAergic or glial cells. After validation of the correct specificity, sensitivity, and spatial distribution of the chimera channelrhodopsin-2 with enhanced yellow fluorescent protein (ChR2-EYFP) by using both 
immunochemistry and fluorescence microscopy, they proceed to $20 \mathrm{~Hz}$ blue laser stimulation $(473 \mathrm{~nm}, 15 \mathrm{~ms}$ pulse width, $85 \mathrm{~mW} \mathrm{~mm}^{-2}$ ) of transfected pyramids through an implanted optrode. Lee and colleagues performed experiments combining optogenetic with functional magnetic resonance imaging (ofMRI) in an anesthetized animal (7.0 T, gradient echo planar imaging, $0.5 \mathrm{~mm} \times 0.5 \mathrm{~mm} \times 0.5 \mathrm{~mm}, 3 \mathrm{~s}$ repetition time). They observed that light stimulation of transfected pyramids resulted in positive BOLD signals in the infected motor cortical area (M1) and in the non-illuminated thalamus. Comparable of MRI results were also observed after activation of pyramidal cells expressing ChR2 in S1 barrel cortex with significantly increased BOLD response in awake as compared to anesthetized mice (Desai et al., 2011; Kahn et al., 2011).

Lee et al. (2010) also studied the BOLD effect after light stimulation of fast-spiking inhibitory interneurons. To overcome the low level of opsin produced when a PV promoter fragment drives its expression, they devised a new strategy combining transgenic mice expressing Cre recombinase under the control of the PV promoter (PV::Cre; Hippenmeyer et al., 2005) and a Credependant AAV. The specificity of this system called flip-excision switch (FLEX) or double inverted open (DIO) reading frame is very high by the introduction of two pairs of heterotypic and antiparallel loxP/lox2272 recombination sites that prevent transcriptional read-through observed with classic lox-STOP-lox cassette (Atasoy et al., 2008; Sohal et al., 2009). Moreover, this system decouples transcriptional strength from the specificity of the PV promoter, allowing expression of ChR2-EYFP by the strong EF1 $\alpha$ promoter. Thus, the expression of the Cre recombinase directly under the control of the endogenous PV locus restricts the expression of ChR2-EYFP to PV-expressing cells (Figure 1). Consequently, if neurons are infected by DIO/FLEX ChR2-EYFP rAAV but devoid of Cre recombinase, they cannot process the cassette and will not express any of the genetic tools carried by the viral construct.

When the motor cortex of infected PV::Cre mice was illuminated, complex responses were observed in BOLD and intracortical electrical signals. BOLD of MRI activation map shows positive BOLD in the illuminated area while a negative BOLD was observed in the flanking region. In the same time, extracellular optrode recording revealed a neuronal excitation in superficial cortical layers and inhibition in deeper layers.

This observation of a possible role of PV-expressing cells in the local control of blood flow was puzzling. PV-expressing cells were never proposed to be involved in local blood control. Indeed, they do not contain vasoactive neuropeptides although a subclass of parvalbumin interneurons contains nitric oxide synthase. It is thus possible that stimulation of parvalbumin interneurons could induce vasodilation by release of NO. The unexpected results of Lee et al. (2010) with PV::Cre mice prompted us to further investigate these optogenetic experiments in an ex vivo set-up used since many years in the laboratory. Here we report that photostimulation of PV containing neurons gives rise to an effective contraction of penetrating arterioles in brain slices. We observed that PV expression is not restricted to fast-spiking GABAergic interneurons (FS-PV) but is also present in a subclass of glutamatergic pyramidal neurons projecting to the thalamus. We

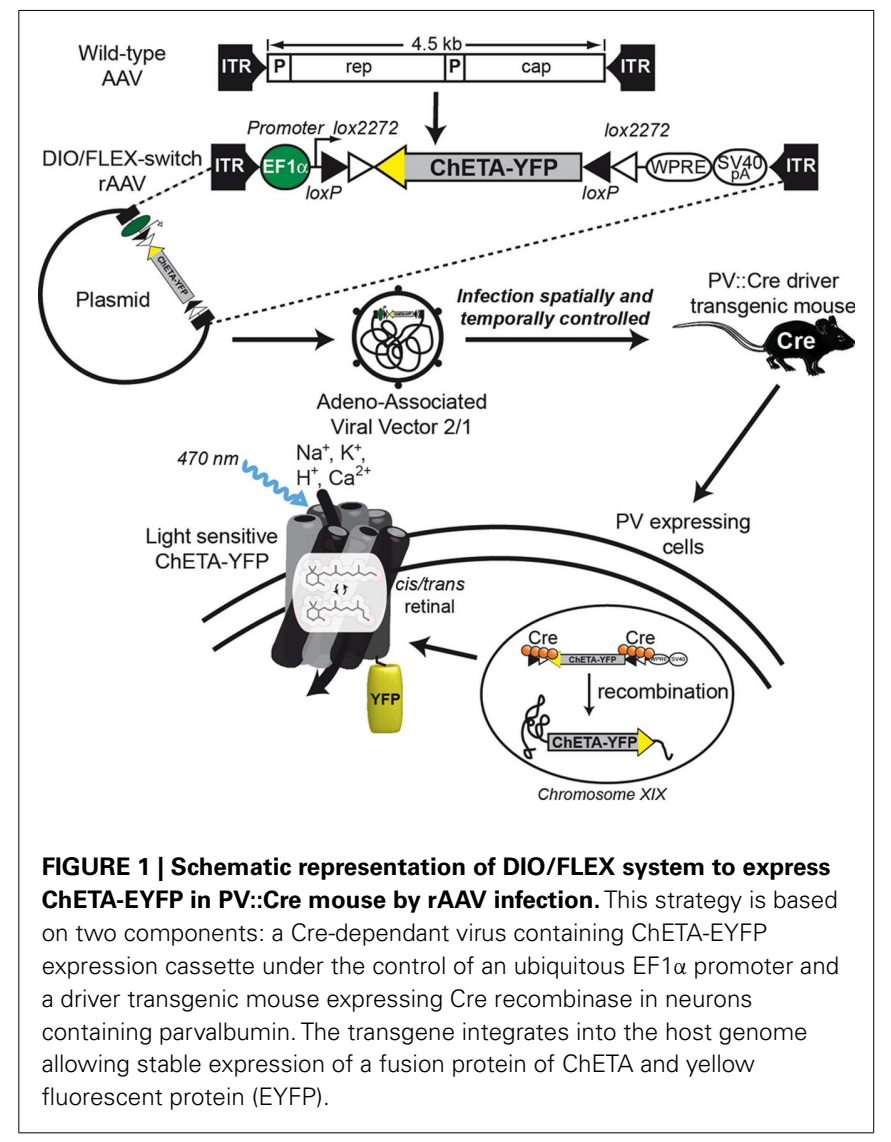

therefore conclude that either FS-PV interneurons or PV-positive pyramids could be implied in vasoconstriction of penetrating arterioles and proposes an efficient optogenetic strategy to address this question.

\section{MATERIALS AND METHODS ANIMALS}

All experiments were carried out in accordance with the European Communities Council Directive of November 24 1986 (86/609/EEC). Transgenic B6;129P2-Pvalbtm1(cre)Arbr/J (PV::Cre) mice were kindly provided by Dr. Poncer (Institut du Fer-à-Moulin, FR). All animals were housed with controlled temperature $\left(23-25^{\circ} \mathrm{C}\right)$ and lighting (12-h dark/light cycle) with food and water available ad libitum.

\section{OPTOGENETIC CONSTRUCT}

Fast-spiking GABAergic interneurons interneurons are divided in several morphological subtypes in the hippocampus and cortex but they share many electrophysiological properties such as shortduration action potentials, no spike-frequency adaptation during short depolarizing current pulses and a spike-frequency up to $200 \mathrm{~Hz}$ (Kawaguchi and Kubota, 1993; Thomson et al., 1996). To be able to study the effects of optogenetic stimulation over a broad range of frequencies, we therefore decide to use an engineered ChR2-E123T Accelerated variant (ChETA). This mutant does feature a higher single-channel conductance, but also a much faster on/off-kinetics, resulting in high fidelity light-driven spiking over 
pulse trains up to $200 \mathrm{~Hz}$ (Gunaydin et al., 2010). Similarly to the genetic construct used in of MRI experiments, the expression of our light sensitive ion channel ChETA was under control of an EF1 $\alpha$ promoter and depends on the presence of Cre recombinase.

\section{ANIMAL ANESTHESIA AND SURGERY}

Prior to surgery, animals were anesthetized with intraperitoneal injections of ketamine $(100 \mathrm{mg} / \mathrm{kg})$, xylazine $(10 \mathrm{mg} / \mathrm{kg})$ with additional doses administered if required. The animals were placed in a stereotaxic frame on a homeothermic blanket (WPI Stoelting, USA) to maintain body temperature at $37^{\circ} \mathrm{C}$ throughout surgical procedure. Just before viral injection and in order to get a larger infection efficacy, mice received a single systemic intraperitoneal injection of mannitol (Carty et al., 2010). Recombinant AAV2/1-EF1 $\alpha:$ :ChETA-EYFP was produced by the Laboratoire de Thérapie Génique - UMR649 (INSERM, Nantes, France) at a titer of $4.3 \times 10^{11} \mathrm{GC} / \mathrm{ml}$ and according to protocol previously described (Hildinger et al., 2001). Thin holes were drilled through the skull under the guidance of a stereomicroscope. After the motorized 34-gage Hamilton syringe was positioned in the center of the barrel field, $1 \mu \mathrm{l}$ of rAAV was injected unilaterally at P30 (Figure 2B) at constant speed with over a 5-min period (Cetin et al., 2006).

\section{SLICE PREPARATION AND ELECTROPHYSIOLOGICAL RECORDINGS}

Two weeks after rAAV injection, PV::Cre mice (P45) were decapitated and brains were quickly removed. A block of tissue containing the S1BF was trimmed, kept in ice-cold artificial cerebro-spinal fluid (aCSF) containing $126 \mathrm{mM} \mathrm{NaCl}, 2.5 \mathrm{mM} \mathrm{KCl}, 1.25 \mathrm{mM}$ $\mathrm{NaH}_{2} \mathrm{PO}_{4}, 2 \mathrm{mM} \mathrm{CaCl}, 1 \mathrm{mM} \mathrm{MgCl} 2,26 \mathrm{mM} \mathrm{NaHCO}, 10 \mathrm{mM}$ glucose, $15 \mathrm{mM}$ sucrose, $1 \mathrm{mM}$ kynurenic acid, and bubbled with $\mathrm{O}_{2}-\mathrm{CO}_{2}(95-5 \%)$. Then, coronal slices (300 $\mu \mathrm{m}$ thick) were prepared as described previously (Schubert et al., 2001). For whole-cell patch-clamp experiments, slices were transferred in the recording chamber and superfused (1-2 $\mathrm{ml} / \mathrm{min}$ ) with oxygenated aCSF. Patch pipettes (4-8 M $\Omega$ ) pulled from borosilicate glass were filled with internal solution containing $144 \mathrm{mM}$ $K$-gluconate, $3 \mathrm{mM} \mathrm{MgCl}_{2}, 0.2 \mathrm{mM}$ EGTA, $10 \mathrm{mM}$ HEPES, $\mathrm{pH}$ $7.2(285 / 295 \mathrm{mOsm})$. Electrophysiological recordings were performed at a holding potential of $-60 \mathrm{mV}$ in current-clamp mode at room temperature $\left(24.5 \pm 1.5^{\circ} \mathrm{C}\right)$ using a patch-clamp amplifier (Multiclamp 700B; Molecular Devices, UK). Data were filtered at $5 \mathrm{kHz}$ and digitized at $50 \mathrm{kHz}$ using an acquisition board (Digidata 1440A/pCLAMP10; Molecular Devices).

\section{LIGHT STIMULATION AND VASCULAR REACTIVITY}

Blood vessels with $>50 \mu \mathrm{m}$ of their length in focus and exhibiting a well-defined luminal diameter $(8-30 \mu \mathrm{m})$ were selected for vascular reactivity. Images of blood vessels were acquired every $15 \mathrm{~s}$ using Image Pro Plus 6.1 (Media Cybernetics, San Diego, CA, USA), and baselines was determined for $5 \mathrm{~min}$. Blood vessels with unstable baseline were discarded from the analyses. Optical stimulation of FS-PV interneurons was performed using the optoLED system (Cairn Research, Faversham, UK), consisting of a 470$\mathrm{nm}, 3.5 \mathrm{~W}$ LED mounted on an BX51WI microscope (Olympus) equipped with infrared DIC optics $(900 \mathrm{~nm}$ ) and epifluorescence (Figure 3C). Targeted optogenetic stimulation was applied during $2 \mathrm{~min}(20 \mathrm{~Hz}, 5 \mathrm{~ms}$ pulse width). The illuminated spot was around $2 \mathrm{~mm}$ (Figure 3A) corresponding to the area of the slice visualized using a $40 \times / 0.8$ numerical aperture water-immersion objective. Luminal diameter changes were quantified off-line at different locations along the blood vessel using custom written routines running within Igor Pro software (WaveMetrics, Portland, OR, USA) to determine the spot of maximum diameter change.
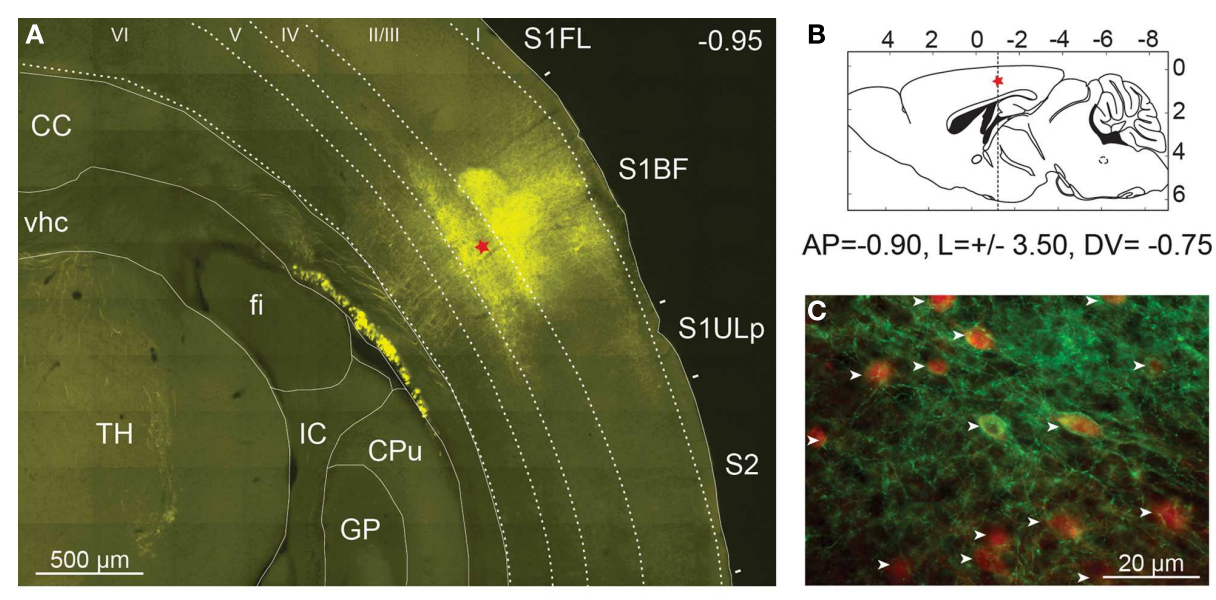

FIGURE 2 | Expression of ChETA-EYFP in the cerebral cortex of mice.

(A) High resolution mosaic images of around 100 individual frames obtained from a 50- $\mu \mathrm{m}$ thick coronal section of $\mathrm{PV}::$ Cre mouse cerebral cortex after 14 days of rAAV infection. Level of expression in somatosensory cortex was controlled by fluorescence microscopy (EYFP filter). The red star indicates the injection site. TH, thalamus; fi, fimbria of hippocampus; vhc, ventral hippocampal commissure; CC, corpus callosum; GP, globus pallidus; IC, internal capsule; $\mathrm{CPu}$, caudate putamen, S1FL, primary somatosensory forelimb cortex; S1BF, primary somatosensory barrel field cortex; S2, secondary somatosensory cortex; S1ULp, primary somatosensory upper limb cortex. (B) Diagram of a sagittal brain slice showing the injection site in the S1BF of the transgenic mouse brain. (C) The cell-type specificity of the viral expression was assayed using immunocytochemistry with an anti-parvalbumin antibody coupled to Alexa Fluor 568 (in red). EYFP expression was found to be largely restricted to parvalbumin expressing neurons (white arrow) in layer $2 / 3$ of $P V:$ :Cre mouse somatosensory cortex. 
A

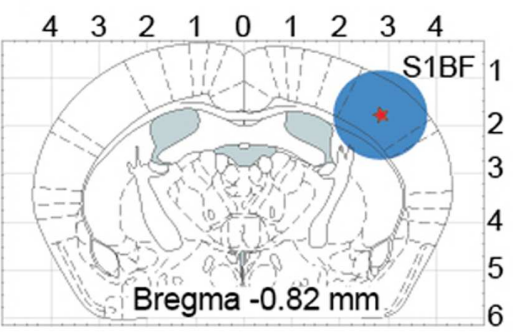

B
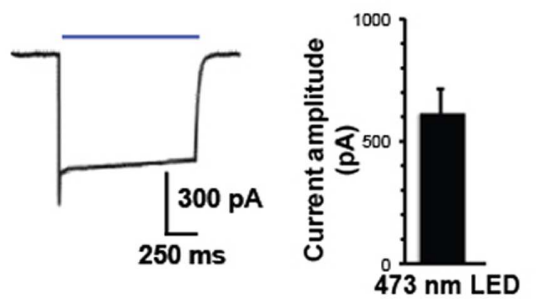
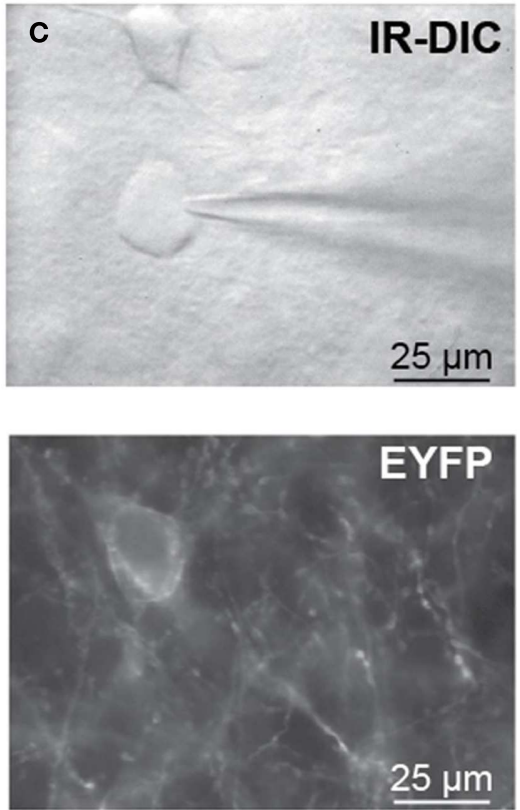

$10 \mathrm{~Hz}$

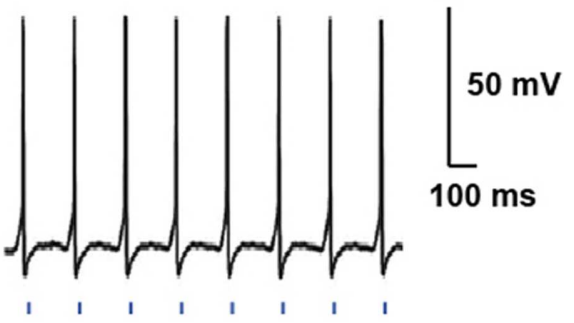

$150 \mathrm{~Hz}$

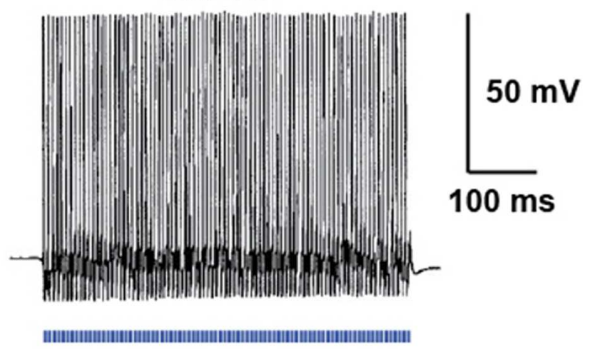

FIGURE 3 | Activation of PV interneurons by blue light. (A) Schematic diagram of a coronal brain slice used in our study. A blue circle represents the size of illuminated area. (B) Voltage-clamp recording demonstrating inward current induced by blue laser light (left). Histogram of peak steady-state photocurrent in response to light stimulation (mean $600 \pm 120 \mathrm{pA}, n=7$ FS cells in three animals, $1 \mathrm{~s}$ stimulus, $35 \mathrm{~mW} \mathrm{~mm}^{-2}$ output power). (C) Bright field (top panel IR-DIC) and fluorescence (bottom panel EYFP) images in the region of recorded neurons. (D) Whole-cell current-clamp recording of $P V$ interneuron expressing ChETA-EYFP in response to patterned light stimulation at 10 or $150 \mathrm{~Hz}$.

\section{RESULTS}

\section{CELL-TYPE-SPECIFIC EXPRESSION OF ChETA-EYFP}

Because successful use of optogenetic techniques relies on sufficient levels and correct expression of the light-activated channels, we performed various controls to evaluate the efficiency of our infection protocol. One advantage of AAV compared to others viruses is the broader spatial spread of transgene expression as confirmed by our observations at both macro and microscopic scales.

Pictures of the exposed skull were taken 2 weeks after viral infection at a $1.25 \times$ magnification using a MZ10F fluorescence stereomicroscope (Leica Microsystems, Wetzlar, Germany) equipped with GFP Plant filter set (Ex: 470/40, Dichroic: 495, Em: 525/50 nm) and interfaced to a Retiga-SRV CCD camera (QImaging, Surrey, Canada). rAAV injection led to a large expression of ChETA-EYFP in the S1BF over a distance of up to $2 \mathrm{~mm}$ around the injection site (data not shown). The animals were then fixed by intracardiac perfusion with $4 \%$ paraformaldehyde and brain was cut in $40 \mu \mathrm{m}$ coronal sections. Fluorescence microscopy and automated mosaic imaging of the whole brain at low magnification revealed a strong ChETA-EYFP fluorescent area of $500 \mu \mathrm{m}$ diameter clearly visible in layers $2 / 3$ and 4 around the injection site (Figure 2A). Fluorescent neuronal fibers were also detected in layers 5 and 6 , in the corpus callosum and in the thalamus. In contrast, no fluorescent signal was observed in the same area on the opposite hemisphere (data not shown).

The cell-type specificity of the viral expression was assayed using immunocytochemistry with a monoclonal primary antibody specific for parvalbumin (Swant, Bellinzona, Switzerland) and an Alexa Fluor 568-coupled secondary antibody (Invitrogen, CA, USA). Using two-color fluorescent microscopy we demonstrated that the expression of transgene was largely restricted to PV-expressing neurons as 95\% (361/380) of ChETAEYFP expressing cells were also PV-positive in layer $2 / 3$ of PV::Cre mouse somatosensory cortex (Figure 2C). Moreover at high magnification, ChETA-EYFP channels appear distributed over both cell body on plasma membranes and neurites (Figure 2C).

\section{OPTOGENETIC STIMULATION OF PV-POSITIVE NEURONS}

Controlled illumination of slices expressing ChETA-EYFP led to spike activity in a temporally precise fashion. In response to blue light stimulation during whole-cell voltage-clamp recordings, FS-PV interneurons exhibit large inward photocurrents (mean $600 \pm 120 \mathrm{pA}, n=7$ FS cells in three animals, $1 \mathrm{~s}$ stimulus, $35 \mathrm{~mW} \mathrm{~mm}^{-2}$ output power, Figure $3 B$ ). FS-PV interneurons reliably fired action potentials in response to patterned blue light stimulation ( $5 \mathrm{~ms}$ pulse width is presented by the blue bars at the bottom of the electrophysiological recordings, $35 \mathrm{~mW} \mathrm{~mm}^{-2}$ output power) up to $150 \mathrm{~Hz}$ (Figure 3D). As described by Gunaydin et al. (2010) for ChETA-EYFP, responses to light were straightforward with neither missed spikes nor plateau potentials over all frequencies tested between 10 and $150 \mathrm{~Hz}$. Light stimulation induced inhibitory postsynaptic potentials (IPSP) on nearby pyramidal cells (data not shown). 


\section{STIMULATION OF PARVALBUMIN EXPRESSING NEURONS ELICITS VASOCONSTRICTION}

In their report Lee et al. have demonstrate with of MRI that activation of parvalbumin-positive cells induce a positive BOLD and a concomitant increase of local neuronal excitation in the illuminated area. More intriguing, they also observed a negative BOLD in the flanking regions (Lee et al., 2010). These results led us to investigate in slices if stimulation of PV-expressing neurons gives rise to a change on the diameters of perforating arterioles. Using infrared video microscopy, we demonstrated that optogenetic stimulation of PV-positive neurons lead to a strong decrease of the diameter of arterioles (Figure 4A). Vasomotor responses were plotted as a percentage relative to the mean diameter measured during the control period (Figure 4B). From Poiseuille's law, it is known that the radius of the blood vessels plays by far the most prominent role in determining the amount of blood flow, $Q=\left(\frac{k P}{l}\right) d^{4}$ where $Q$ is flow, $P$ is the pressure difference, $d$ is the diameter, $l$ is the length, and $k$ is a constant depending of the viscosity. After $6 \mathrm{~min}$, we observed a $5 \%$ contraction of vessels $(n=5 ; p<0.05)$ what represents a significant decrease of blood flow by a value of more than $20 \%$. Although all recording of vessels were performed in brain slices, these results are in agreement with those measured in the cerebral cortex in vivo (Stefanovic et al., 2008; Mace et al., 2011).

\section{DISCUSSION \\ HOW ACTIVATION OF THE BRAIN TRANSMUTES IN FUNCTIONAL HYPEREMIA: NEUROGENIC VS. METABOLIC HYPOTHESIS}

Precise mechanisms involved in functional hyperemia are still poorly understood. At present, an intense debate among neuroscientists exists with two hypotheses, the "metabolic" and the "neurogenic" (Estrada and DeFelipe, 1998; Hamel, 2006). Neuronal activity is the principal energy-consuming process in the brain. The metabolic hypothesis assumes a causal link between neuronal energy demand and regulation of local CBF. The general assumption, which is supported by positron emission tomography (PET) findings showing comparable functional increases in blood flow and glucose uptake (Raichle and Mintun, 2006), is that $\mathrm{CBF}$ is coupled to regional glucose utilization, which in turn is directly related to neuronal activity (Magistretti, 2006). Excitatory neuronal activity releases glutamate that activates glia through metabotropic glutamate receptors. The activation of glial cells will induce at the same time an increase in the diameter of nearby blood vessels and increase of glucose uptake. In this metabolic hypothesis, the activity-dependent regulation of local CBF is a feedback mechanism that does not anticipate possible demand (Rossier, 2009). In contrast with this metabolic feedback hypothesis, the neurogenic hypothesis (Estrada and DeFelipe, 1998; Hamel, 2006) describes a feed forward mechanism where the hyperemia evoked by cerebral activation is linked to neuronal synaptic signaling rather than to the metabolic needs of the tissue (Leithner et al., 2010; Lindauer et al., 2010). Previous studies demonstrated three neuronal elements that are candidate for controlling local CBF: interneurons (Abounader and Hamel, 1997; Cauli et al., 2004), pyramids (Abounader and Hamel, 1997; Zonta et al., 2003; Filosa et al., 2006; Iadecola and Nedergaard, 2007; Lecrux et al., 2011), and subcortical nuclei afferent pathways (Raichle et al., 1975; Cohen et al., 1996; Abounader and Hamel, 1997; Krimer et al., 1998; Yamada et al., 2001; Hamel, 2004; Gordon et al., 2008; Jones et al., 2008).

\section{RECENT IN VIVO EXPERIMENTS IN RODENTS INDICATE THE POSSIBLE EXISTENCE OF AN INTRINSIC BRAIN NEURONAL NETWORK THAT CONTROLS THE NEOCORTICAL LOCAL BLOOD FLOW}

Several in vivo experiments with various techniques have already indicated that whisker pad stimulation is accompanied by blood flow increase in the contralateral barrel field but also by blood flow decrease in other part of the brain. In two recent reports, one from (Alonso Bde et al., 2008; Boorman et al., 2010) describing $\mathrm{fMRI}$ experiments with the rodent whisker-to-barrel system, whisker pad stimulation was accompanied by a positive BOLD in the homotypic contralateral barrel field but also by a negative BOLD in the ipsilateral primary somatosensory cortex (S1) and/or in deeper surrounding areas of the contralateral cortex.
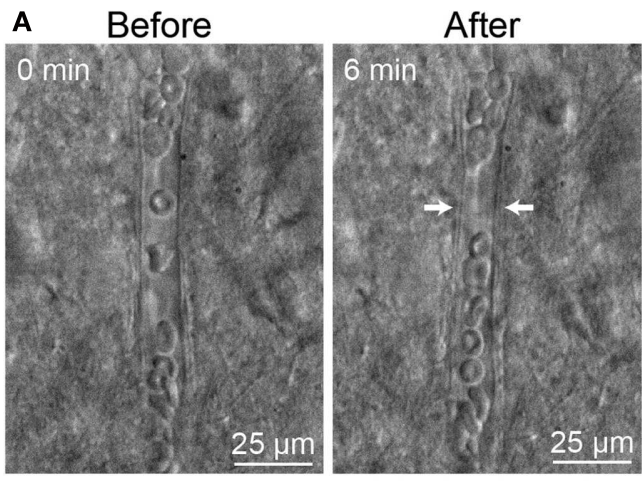

FIGURE 4 | Vasoconstriction induced by optogenetic stimulation of PV-expressing neurons. (A) Infrared microscopy images of a blood vessel in the somatosensory cortex showing changes of the luminal diameter after light stimulation of PV interneurons. Images of the microvessels were acquired every $15 \mathrm{~s}$ after a control period of $5 \mathrm{~min}$.

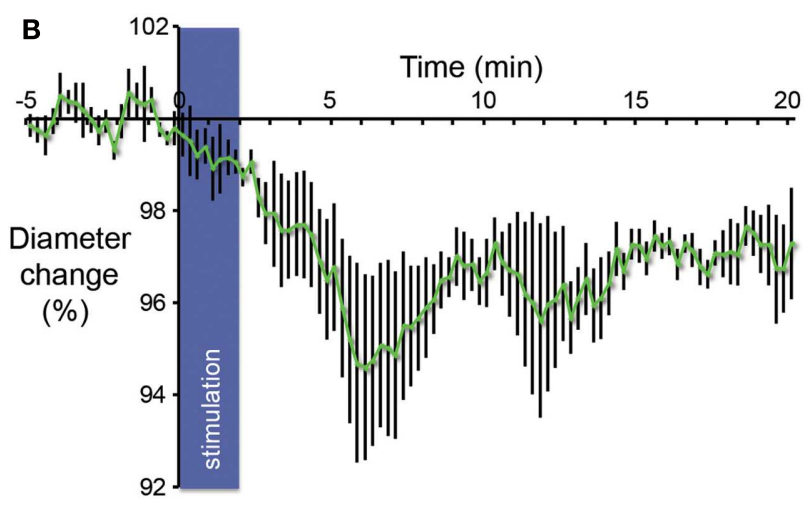

Arrows indicate region of high vascular reactivity. Note the accumulation of red blood cells on both sides of the arrows in the right panel. (B) Mean vascular constriction $\pm \operatorname{SEM}(n=5)$ induced by 2 min stimulation at $20 \mathrm{~Hz}$ $\left(473 \mathrm{~nm}, 5 \mathrm{~ms}\right.$ pulse width, $35 \mathrm{~mW} \mathrm{~mm}^{-2}$ ) in the layer II/III of the somatosensory cortex 
In order to explain these data we propose that a neuronal circuitry is devoted to an exquisite regulation of the local blood flow. Kleinfeld et al. (2011) also proposed the idea that a specialized neuronal system is locked to the precise local blood flow control in a recent review. Almost 10 years ago, several fMRI studies had already described that besides positive BOLD and blood flow signal changes in the activated area, robust negative responses can be detected independently in the absence or simultaneously with the positive responses (Brefczynski and DeYoe, 1999; Allison et al., 2000; Shmuel et al., 2002). More recently Devor et al. (2008) reached the same conclusion by intrinsic optical spectroscopic imaging when they measured hemodynamic changes in response to forepaw stimulation. They showed that an increase of blood perfusion in the contralateral cortex is followed by a decrease in the ipsilateral somatosensory cortex (Devor et al., 2008).

In conclusion, changes in the redistribution of the cerebral local blood flow following brain activation are much more complex than initially anticipated. If activation of pyramids and release of glutamate could explain the positive BOLD response via the stimulation of astrocytes, it could not explain the negative BOLD response in the surrounding areas and in the ipsilateral cortex. Negative BOLD is generally considered to be the manifestation of an increase activity of GABAergic inhibitory interneurons (Logothetis et al., 2001; Logothetis, 2008). The puzzling problem is to understand what classes of interneurons are activated and how their activation is mediated. In the present general knowledge, the local blood flow redistribution after brain activation appears complex with a simultaneous increase in some regions of the brain and a decrease in others. The network controlling local blood flow could be considered as a connected regulatory system in his own right. The neurovascular regulatory system could not be explained solely by local circuitry involving interneurons and pyramidal cells. Possible long projections are to be taken into account to explain the decreased perfusion in the ipsilateral cortex observed by several investigators. Direct transcallosal projections between the two somatosensory cortices are a possibility although multisynaptic connections via the motor cortex or the thalamus have also to be taken into account. Here we enter in an uncharted territory.

If we restrict our analysis to the identification of the last neuronal relays, i.e., interneurons and pyramids, many ex vivo experiments from our group have clearly demonstrated that distinct subclasses of interneurons containing VIP, NOS, SOM, and NPY control directly the tone of the smooth muscles of the arterioles (Cauli et al., 2004; Rancillac et al., 2006). Indeed, smooth muscles of the penetrating arterioles are ideally localized to be the main regulators of blood flow and pressure in the cortical cortex (Hillman, 2007; Nishimura et al., 2007). This regulation occurs at the precapillary level through sphincters that are involved in a localized control of capillary tone (Peppiatt et al., 2006; Attwell et al., 2010; Hamilton et al., 2010).

\section{OPTOGENETIC STIMULATION OF PV CONTAINING NEURONS AND THE CONTROL LOCAL BLOOD FLOW}

One main advantage of our experiments in slices is the direct visualization of parenchymal microvessels movements. Although the blood vessels in this preparation lack intraluminal flow and pressure, which have been shown to play a role in the regulation of tone (Johansson, 1989; Mellander, 1989), the physiologic reactivity of vessels in the brain slice preparation has been demonstrated (Sagher et al., 1993; Fergus et al., 1996). Moreover, it was previously reported that vascular responses observed ex vivo are really slow compared to in vivo responses ( $5 \mathrm{~min}$ vs. $1 \mathrm{~s}$ respectively; Cauli et al., 2004; Rancillac et al., 2006). Our results in Figure 4 show that increased activity of cells expressing PV results in vasoconstriction in neighboring perforating arterioles. How to explain these results? PV interneurons were never described to mediate vascular responses. Moreover, PV interneurons do not contain any known vasoactive peptides although a subpopulation expresses nitric oxide synthase. If NO was release by a subpopulation of PV interneurons, a vasodilatation should have been expected and not a vasoconstriction as observed in our experiments. It is unlikely that PV interneurons regulates directly $\mathrm{CBF}$ but they could act as a relay to inhibit local or distal interneuron involved in a vasodilation tone. FS-PV interneurons could thus lead to vasoconstriction by a decreased release of VIP and/or NOS following inhibition of interneurons containing these vasodilatating substances. PV interneurons could also be in the middle of an inhibitory loop whose final effect could relief the inhibition of neurogliaform interneurons releasing the potent vasoconstrictor peptide NPY.

Another possible explanation could be that these vasoconstrictions are not generated by PV interneurons but by PV-expressing pyramidal neurons. This hypothesis is supported by previous studies showing that a subset of pyramids from the primary somatosensory, motor, and visual areas expresses PV (McMullen et al., 1994; Preuss and Kaas, 1996; Tanahira et al., 2009). Indeed as shown in Figure 2A, we observed efferent fibers projecting from the cortical layer $\mathrm{V}$ and $\mathrm{VI}$ of the cortex to the ventral posterolateral nucleus (VPL) of the thalamus and through the corpus callosum, while the virus was injected into S1BF. This result suggests that these long projection neurons could belong to a subset of pyramids expressing PV. In this scenario, pyramidal cell could therefore be implicated in vasoconstriction observed after by light stimulation of ChETA-EYFP in slices. This assumption about involvement of pyramids in CBF control is consistent with previous studies that demonstrate their roles either directly by the release of COX-2derived dilatory prostaglandins or indirectly by astrocytic release of EETs (Lecrux et al., 2011). Nevertheless, the proposal that a subset of pyramids expressing PV is part of the neuronal system controlling blood flow is still intriguing.

Together, vasoconstrictions following optogenetic stimulation of PV-expressing neurons could results from interneurons and/or pyramids activation. Our results are in accordance with the role of local cortical neurons in the regulation of CBF since all afferent and efferent fibers between the cortex and others subcortical nuclei are cut in coronal brain slices used in these experiments. These findings bring new insight to the complex mechanisms of the neurovascular coupling and require further investigation.

\section{ACKNOWLEDGMENTS}

We thank Marcel Leopoldie for animal husbandry. This work was supported by the French National Research Agency (ANRSVSE4BRAINVASC) and by the Fondation Pour les Sciences du Cerveau. 


\section{REFERENCES}

Abounader, R., and Hamel, E. (1997). Associations between neuropeptide Y nerve terminals and intraparenchymal microvessels in rat and human cerebral cortex. J. Comp. Neurol. 388, 444-453.

Allison, J. D., Meador, K. J., Loring, D. W., Figueroa, R. E., and Wright, J. C. (2000). Functional MRI cerebral activation and deactivation during finger movement. Neurology 54, 135-142.

Alonso Bde, C., Lowe, A. S., Dear, J. P., Lee, K. C., Williams, S. C., and Finnerty, G. T. (2008). Sensory inputs from whisking movements modify cortical whisker maps visualized with functional magnetic resonance imaging. Cereb. Cortex 18, 1314-1325.

Atasoy, D., Aponte, Y., Su, H. H., and Sternson, S. M. (2008). A FLEX switch targets Channelrhodopsin-2 to multiple cell types for imaging and long-range circuit mapping. $J$. Neurosci. 28, 7025-7030.

Attwell, D., Buchan, A. M., Charpak, S., Lauritzen, M., Macvicar, B. A., and Newman, E. A. (2010). Glial and neuronal control of brain blood flow. Nature 468, 232-243.

Boorman, L., Kennerley, A. J., Johnston, D., Jones, M., Zheng, Y., Redgrave, P., and Berwick, J. (2010). Negative blood oxygen level dependence in the rat: a model for investigating the role of suppression in neurovascular coupling. J. Neurosci. 30, 4285-4294.

Brefczynski, J. A., and DeYoe, E. A. (1999). A physiological correlate of the "spotlight" of visual attention. Nat. Neurosci. 2, 370-374.

Carty, N., Lee, D., Dickey, C., CeballosDiaz, C., Jansen-West, K., Golde, T. E., Gordon, M. N., Morgan, D., and Nash, K. (2010). Convectionenhanced delivery and systemic mannitol increase gene product distribution of AAV vectors 5, 8, and 9 and increase gene product in the adult mouse brain. J. Neurosci. Methods 194, 144-153.

Cauli, B., Tong, X. K., Rancillac, A., Serluca, N., Lambolez, B., Rossier, J., and Hamel, E. (2004). Cortical GABA interneurons in neurovascular coupling: relays for subcortical vasoactive pathways. J. Neurosci. 24, 8940-8949.

Cetin, A., Komai, S., Eliava, M., Seeburg, P. H., and Osten, P. (2006). Stereotaxic gene delivery in the rodent brain. Nat. Protoc. 1, 3166-3173.

Chow, B. Y., Han, X., Dobry, A. S., Qian, X., Chuong, A. S., Li, M., Henninger, M. A., Belfort, G. M., Lin, Y., Monahan, P. E., and Boyden, E.
S. (2010). High-performance genetically targetable optical neural silencing by light-driven proton pumps. Nature 463, 98-102.

Cohen, Z., Bonvento, G., Lacombe, P., and Hamel, E. (1996). Serotonin in the regulation of brain microcirculation. Prog. Neurobiol. 50, 335-362.

Desai, M., Kahn, I., Knoblich, U., Bernstein, J., Atallah, H., Yang, A., Kopell, N., Buckner, R. L., Graybiel, A. M., Moore, C. I., and Boyden, E. S. (2011). Mapping brain networks in awake mice using combined optical neural control and fMRI. J. Neurophysiol. 105, 1393-1405.

Devor, A., Hillman, E. M., Tian, P., Waeber, C., Teng, I. C., Ruvinskaya, L., Shalinsky, M. H., Zhu, H., Haslinger, R. H., Narayanan, S. N., Ulbert, I., Dunn, A. K., Lo, E. H., Rosen, B. R., Dale, A. M., Kleinfeld, D., and Boas, D. A. (2008). Stimulusinduced changes in blood flow and 2-deoxyglucose uptake dissociate in ipsilateral somatosensory cortex. $J$. Neurosci. 28, 14347-14357.

Estrada, C., and DeFelipe, J. (1998). Nitric oxide-producing neurons in the neocortex: morphological and functional relationship with intraparenchymal microvasculature. Cereb. Cortex 8, 193-203.

Fergus, A., Jin, Y., Thai, Q. A., Kassell, N. F., and Lee, K. S. (1996). Tonic protein kinase C-mediated vasoconstriction is unmasked when nitric oxide synthase is inhibited in cerebral microvessels. Neuroscience 74, 927-934.

Filosa, J. A., Bonev, A. D., Straub, S. V., Meredith, A. L., Wilkerson, M. K., Aldrich, R. W., and Nelson, M.T. (2006). Local potassium signaling couples neuronal activity to vasodilation in the brain. Nat. Neurosci. 9, 1397-1403.

Gordon, G. R., Choi, H. B., Rungta, R. L., Ellis-Davies, G. C., and Macvicar, B. A. (2008). Brain metabolism dictates the polarity of astrocyte control over arterioles. Nature 456, 745-749.

Gunaydin, L. A., Yizhar, O., Berndt, A., Sohal, V. S., Deisseroth, K., and Hegemann, P. (2010). Ultrafast optogenetic control. Nat. Neurosci. 13, 387-392.

Iadecola, C., and Nedergaard, M. (2007). Glial regulation of the cerebral microvasculature. Nat. Neurosci. 10, 1369-1376.

Hamel, E. (2004). Cholinergic modulation of the cortical microvascular bed. Prog. Brain Res. 145, 171-178.

Hamel, E. (2006). Perivascular nerves and the regulation of cerebrovascular tone. J. Appl. Physiol. 100, 1059-1064.
Hamilton, N. B., Attwell, D., and Hall, C. N. (2010). Pericytemediated regulation of capillary diameter: a component of neurovascular coupling in health and disease. Front. Neuroenergetics 2:5. doi:10.3389/fnene.2010.00005

Hildinger, M., Auricchio, A., Gao, G., Wang, L., Chirmule, N., and Wilson, J. M. (2001). Hybrid vectors based on adeno-associated virus serotypes 2 and 5 for muscle-directed gene transfer. J. Virol. 75, 6199-6203.

Hillman, E. M. (2007). Optical brain imaging in vivo: techniques and applications from animal to man. $J$. Biomed. Opt. 12, 051402.

Hippenmeyer, S., Vrieseling, E., Sigrist, M., Portmann, T., Laengle, C., Ladle, D. R., and Arber, S. (2005). A developmental switch in the response of DRG neurons to ETS transcription factor signaling. PLoS Biol. 3, e159. doi:10.1371/journal.pbio.0030159

Johansson, B. (1989). Myogenic tone and reactivity: definitions based on muscle physiology. J. Hypertens. Suppl. 7, S5-S8; discussion S9.

Jones, M., Devonshire, I. M., Berwick, J., Martin, C., Redgrave, P., and Mayhew, J. (2008). Altered neurovascular coupling during informationprocessing states. Eur. J. Neurosci. 27 , 2758-2772.

Kahn, I., Desai, M., Knoblich, U. Bernstein, J., Henninger, M., Graybiel, A. M., Boyden, E. S., Buckner, R. L., and Moore, C. I. (2011). Characterization of the functional MRI response temporal linearity via optical control of neocortical pyramidal neurons. J. Neurosci. 31, 15086-15091.

Kawaguchi, Y., and Kubota, Y. (1993). Correlation of physiological subgroupings of nonpyramidal cells with parvalbumin- and calbindin D28k-immunoreactive neurons in layer $\mathrm{V}$ of rat frontal cortex. J. Neurophysiol. 70, 387-396.

Kleinfeld, D., Blinder, P., Drew, P. J. Driscoll, J. D., Muller, A., Tsai, P. S., and Shih, A. Y. (2011) A guide to delineate the logic of neurovascular signaling in the brain. Front Neuroenergetics 3:1. doi:10.3389/fnene.2011.00001

Krimer, L. S., Muly, E. C. III, Williams, G. V., and Goldman-Rakic, P. S. (1998). Dopaminergic regulation of cerebral cortical microcirculation. Nat. Neurosci. 1, 286-289.

Lecrux, C., Toussay, X., Kocharyan, A., Fernandes, P., Neupane, S., Levesque, M., Plaisier, F., Shmuel, A., Cauli, B., and Hamel, E. (2011). Pyramidal neurons are "neurogenic hubs" in the neurovascular coupling response to whisker stimulation. J. Neurosci. 31, 9836-9847.

Lee, J. H., Durand, R., Gradinaru, V., Zhang, F., Goshen, I., Kim, D. S., Fenno, L. E., Ramakrishnan, C., and Deisseroth, K. (2010). Global and local fMRI signals driven by neurons defined optogenetically by type and wiring. Nature 465, 788-792.

Leithner, C., Muller, S., Fuchtemeier, M., Lindauer, U., Dirnagl, U., and Royl, G. (2010). Determination of the brain-blood partition coefficient for water in mice using MRI. J. Cereb. Blood Flow Metab. 30, 1821-1824.

Lindauer, U., Dirnagl, U., Fuchtemeier, M., Bottiger, C., Offenhauser, N., Leithner, C., and Royl, G. (2010). Pathophysiological interference with neurovascular coupling - when imaging based on hemoglobin might go blind. Front Neuroenergetics 2:25. doi:10.3389/fnene.2010.00025

Logothetis, N. K. (2008). What we can do and what we cannot do with fMRI. Nature 453, 869-878.

Logothetis, N. K., Pauls, J., Augath, M., Trinath, T., and Oeltermann, A. (2001). Neurophysiological investigation of the basis of the fMRI signal. Nature 412, 150-157.

Mace, E., Montaldo, G., Cohen, I., Baulac, M., Fink, M., and Tanter, M. (2011). Functional ultrasound imaging of the brain. Nat. Methods 8, 662-664.

Magistretti, P. J. (2006). Neuron-glia metabolic coupling and plasticity. $J$. Exp. Biol. 209, 2304-2311.

Martin, C., Martindale, J., Berwick, J., and Mayhew, J. (2006). Investigating neural-hemodynamic coupling and the hemodynamic response function in the awake rat. Neuroimage 32, 33-48.

McMullen, N. T., Smelser, C. B., and Rice, F. L. (1994). Parvalbumin expression reveals a vibrissa-related pattern in rabbit SI cortex. Brain Res. 660, 225-231.

Mellander, S. (1989). Functional aspects of myogenic vascular control. J. Hypertens. Suppl. 7, S21-S30; discussion S31.

Nishimura, N., Schaffer, C. B., Friedman, B., Lyden, P. D., and Kleinfeld, D. (2007). Penetrating arterioles are a bottleneck in the perfusion of neocortex. Proc. Natl. Acad. Sci. U.S.A. 104, 365-370.

Peppiatt, C. M., Howarth, C., Mobbs, P., and Attwell, D. (2006). Bidirectional control of CNS capillary diameter by pericytes. Nature 443, 700-704.

Preuss, T. M., and Kaas, J. H. (1996) Parvalbumin-like immunoreactivity of layer $\mathrm{V}$ pyramidal cells in the motor and somatosensory cortex 
of adult primates. Brain Res. 712, 353-357.

Raichle, M. E., Hartman, B. K., Eichling, J. O., and Sharpe, L. G. (1975). Central noradrenergic regulation of cerebral blood flow and vascular permeability. Proc. Natl. Acad. Sci. U.S.A. 72, 3726-3730.

Raichle, M. E., and Mintun, M. A. (2006). Brain work and brain imaging. Annu. Rev. Neurosci. 29, 449-476.

Rancillac, A., Rossier, J., Guille, M., Tong, X. K., Geoffroy, H., Amatore, C., Arbault, S., Hamel, E., and Cauli, B. (2006). Glutamatergic control of microvascular tone by distinct GABA neurons in the cerebellum. J. Neurosci. 26, 6997-7006.

Rossier, J. (2009). Wiring and plumbing in the brain. Front. Hum. Neurosci. 3:2. doi:10.3389/neuro.09.002.2009

Sagher, O., Zhang, X. Q., Szeto, W., Thai, Q. A., Jin, Y., Kassell, N. F., and Lee, K. S. (1993). Live computerized videomicroscopy of cerebral microvessels in brain slices. J. Cereb. Blood Flow Metab. 13, 676-682.

Schubert, D., Staiger, J. F., Cho, N., Kotter, R., Zilles, K., and Luhmann, H. J. (2001). Layer-specific intracolumnar and transcolumnar functional connectivity of layer $\mathrm{V}$ pyramidal cells in rat barrel cortex. J. Neurosci. 21, 3580-3592.

Shmuel, A., Yacoub, E., Pfeuffer, J., Van De Moortele, P. F., Adriany, G., Hu, X., and Ugurbil, K. (2002). Sustained negative BOLD, blood flow and oxygen consumption response and its coupling to the positive response in the human brain. Neuron 36, 1195-1210.

Sohal, V. S., Zhang, F., Yizhar, O., and Deisseroth, K. (2009). Parvalbumin neurons and gamma rhythms enhance cortical circuit performance. Nature 459, 698-702.

Stefanovic, B., Hutchinson, E., Yakovleva, V., Schram, V., Russell, J. T., Belluscio, L., Koretsky, A. P., and Silva, A. C. (2008). Functional reactivity of cerebral capillaries. J. Cereb. Blood Flow Metab. 28, 961-972.

Tanahira, C., Higo, S., Watanabe, K., Tomioka, R., Ebihara, S., Kaneko, T., and Tamamaki, N. (2009). Parvalbumin neurons in the forebrain as revealed by parvalbumin-Cre transgenic mice. Neurosci. Res. 63, 213-223.

Thomson, A. M., West, D. C., Hahn, J., and Deuchars, J. (1996). Single axon IPSPs elicited in pyramidal cells by three classes of interneurones in slices of rat neocortex. J. Physiol. (Lond.) 496(Pt 1), 81-102.
Urban, A., and Rossier, J. (2012). "Genetic targeting of specific neuronal cell types in the cerebral cortex," in Progress in Brain Research, Chapter 9, eds K. P. Thomas and S. B. Edward (Paris: Elsevier), 163-192.

Wiest, M. C., Bentley, N., and Nicolelis, M. A. (2005). Heterogeneous integration of bilateral whisker signals by neurons in primary somatosensory cortex of awake rats. J. Neurophysiol. 93, 2966-2973.

Yamada, M., Lamping, K. G., Duttaroy, A., Zhang, W., Cui, Y., Bymaster, F. P., Mckinzie, D. L., Felder, C. C., Deng, C. X., Faraci, F. M., and Wess, J. (2001). Cholinergic dilation of cerebral blood vessels is abolished in $\mathrm{M}(5)$ muscarinic acetylcholine receptor knockout mice. Proc. Natl. Acad. Sci. U.S.A. 98, 14096-14101.

Zhang, F., Gradinaru, V., Adamantidis, A. R., Durand, R., Airan, R. D., De Lecea, L., and Deisseroth, K. (2010). Optogenetic interrogation of neural circuits: technology for probing mammalian brain structures. Nat. Protoc. 5, 439-456.

Zonta, M., Angulo, M. C., Gobbo, S. Rosengarten, B., Hossmann, K. A., Pozzan, T., and Carmignoto, G. (2003). Neuron-to-astrocyte signaling is central to the dynamic control of brain microcirculation. Nat. Neurosci. 6, 43-50.

Conflict of Interest Statement: The authors declare that the research was conducted in the absence of any commercial or financial relationships that could be construed as a potential conflict of interest.

Received: 26 January 2012; paper pending published: 13 February 2012; accepted: 16 May 2012; published online: 15 June 2012.

Citation: Urban A, Rancillac A, Martinez L and Rossier J (2012) Deciphering the neuronal circuitry controlling local blood flow in the cerebral cortex with optogenetics in PV::Cre transgenic mice. Front. Pharmacol. 3:105. doi: 10.3389/fphar.2012.00105

This article was submitted to Frontiers in Neuropharmacology, a specialty of Frontiers in Pharmacology.

Copyright (c) 2012 Urban, Rancillac, Martinez and Rossier. This is an openaccess article distributed under the terms of the Creative Commons Attribution Non Commercial License, which permits non-commercial use, distribution, and reproduction in other forums, provided the original authors and source are credited. 